\title{
Localization of the dopamine transporter gene, Dat1, on mouse Chromosome 13
}

\author{
A.C. Lossie, ${ }^{1}$ D.J. Vandenbergh, ${ }^{2}$ G.R. Uhl, ${ }^{2}$ S.A. Camper ${ }^{1}$ \\ 'Department of Human Genetics, University of Michigan, Ann Arbor, Michigan 48109-0618, USA \\ ${ }^{2}$ Laboratory of Molecular Neurobiology, National Institute on Drug Abuse, Addiction Research Center, and Departments of Neurology and \\ Neuroscience, Johns Hopkins University School of Medicine, Baltimore, Maryland 21224, USA
}

Received: 13 September 1993 / Accepted: 5 October 1993

The human dopamine transporter, DAT, plays a central role in the regulation of dopaminergic transmission. DAT removes released dopamine from the synaptic cleft and transports it to presynaptic terminals, thereby terminating dopaminergic neurotransmission. DAT belongs to a family of sodium-dependent neurotransmitter transporters whose members contain putative 12 transmembrane domains. Human disorders such as substance abuse, Tourette's syndrome, and Parkinson's disease may have genetic components and have been implicated in dysfunction of dopaminergic neurons (Pauls and Leckman 1986; Smith et al. 1992). Many abused substances also act on dopaminergic systems. Cocaine binds directly to DAT and inhibits the transport of dopamine into the dopaminergic neurons. This dopaminergic transmission inhibition is thought to be the main mechanism associated with the reinforcing effects of cocaine abuse (Ritz et al. 1987). Localizing the DAT gene in the mouse may be of use in further understanding dopamine-related disorders and the role of DAT in dopaminergic neuron function.

The human dopamine transporter gene, DAT1, has been localized to human Chr $5 \mathrm{p} 15.3$ by in situ hybridization (Giros et al. 1992; Vandenbergh et al. 1992). The synteny homology between mouse and human chromosomes suggested that mouse DatI would map to Chr 11, 13,15 , or 18 . We extended the linkage analysis of an $M$. m. castaneus intersubspecific backcross $(\mathrm{DF} / \mathrm{B}-d f / d f \times$ CASA/Rk) $\mathrm{F}_{1} \times(\mathrm{DF} / \mathrm{B}-d f / d f$; Buckwalter et al. 1991) that had been previously characterized for $\mathrm{Chr} 5,11$, and 18 , to include the characterization of $\mathrm{Chr} 13$. We report the localization of Datl in relation to four polymorphic simple

Correspondence to: S.A. Camper sequence repeat markers: D13Mit10, $I l-9$ (interleukin-9), D13Mit8, and D13Mit32 (Dietrich et al. 1992).

The simple sequence repeat markers were mapped by PCR amplification with a 96-well MJ machine as previously stated (Dietrich et al. 1992), except that $\gamma^{32}$ P-ATPlabeled primers were diluted to a final concentration of 0.7 $\mu \mathrm{Ci}$ per reaction, and $100 \mu \mathrm{g} / \mathrm{ml} \mathrm{BSA}$ was added to the reaction mixture. Samples were denatured at $92^{\circ} \mathrm{C}$ for 10 min, cooled to $0^{\circ} \mathrm{C}$ for at least $5 \mathrm{~min}$, separated by electrophoresis on $6 \%$ acrylamide, $8 \mathrm{M}$ urea denaturing sequencing gels, and visualized by autoradiography.

Amplification of the simple sequence repeat markers produced DF/B-df/df-specific and CASA/Rk-specific products, which allowed us to create a map of mouse Chromosome (Chr) 13 and link Datl to the chromosome. A Dat 1 RFLP was detected by standard Southern blot analysis. The Datl probe consisted of a 2.3-kb EcoRI fragment, from the $5^{\prime}$ region of the rat DAT1 cDNA. Hybridization with this probe revealed a polymorphism in genomic DNA digested with $B s t$ EII. The resulting fragments specific for the CASA/Rk allele were 16 and $7.5 \mathrm{~kb}$; those specific for the $\mathrm{DF} / \mathrm{B}-d f / d f$ allele were $13,4.5$, and $4.2 \mathrm{~kb}$. Fragments of 12 and $6.8 \mathrm{~kb}$ were present in both CASA/Rk and $\mathrm{DF} / \mathrm{B}-d f / d f$ genomic DNA.

We established the unambiguous gene order on the basis of haplotype analysis of 51 backcross progeny (Fig. 1). Using these and additional animals, we calculated the intergenic distance (cM \pm estimated standard error) to be:

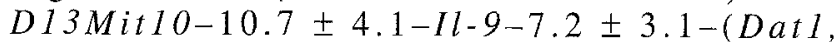
D13Mit8)-24.4 $\pm 4.5-D 13 M i t 32$ (Fig. 2). No recombination was detected between Dat1 and D13Mit8 in 70 backcross progeny $(0 \pm 4.2 \mathrm{cM}, 95 \%$ confidence level). The genetic order and distances we found correlate with previously published results for simple sequence repeat markers (Dietrich et al. 1992). 


\section{D13Mit10 $\square \square \square \square \square \square \square \square \square \square$
H-9 $\square \square \square \square \square \square \square \square \square \square$
Dat1; D13Mit8 $\square \square \square \square \square \square \square \square \square$
D13Mit32 $\square \square \square \square \square \square \square \square \square$
201322135401}

Fig. 1. Haplotype distribution of 51 backcross progeny. Each column represents a chromosomal haplotype. The number of animals observed with each haplotype is given below the column. Animals were scored at each locus (left) as heterozygous for the $M . m$. castaneus and DF/B-df/df al-

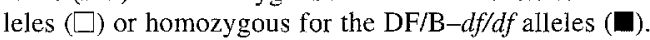

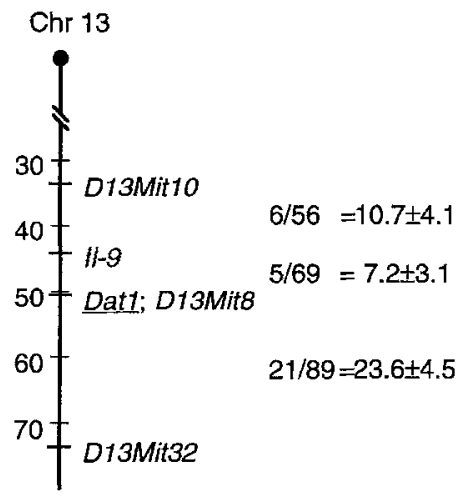

Fig. 2. Genetic map of Chr 13. A linkage map of mouse Chr 13 was constructed from the haplotype distribution in Fig. 1. The map distances, in $\mathrm{cM}$, were calculated from the recombinant fraction observed for each interval (right). The anchor locus, $I-9$, was used to assess the position of these loci relative to the centromere (left, in $\mathrm{cM}$ ).

Dat1 maps to the region of mouse Chr 13 that exhibits an extensive domain of synteny homology with human Chr 5. The nine loci that are the basis for the synteny homology span the entire end of Chr 13, from approximately 40 map units to the telomere. Using the reference locus Il-9 to compare our map of Chr 13 with the consensus map (Justice and Stephenson 1992), we estimate that DatI maps

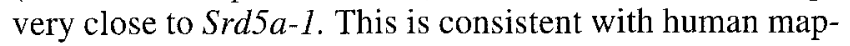
ping studies that place SRD5A1 on 5p15 and DAT1 on $5 \mathrm{p} 15.3$.

The only neuron-specific mouse mutation located in the same region of Chr 13 as Datl is purkinje cell degeneration, $p c d$. Although multiple neuronal cell types die in mice with $p c d$ (O'Gorman and Sidman 1985), none are clearly related to dopamine function. In addition, the defect is thought to be intrinsic to the degenerating cells (Mullen 1977) and therefore difficult to directly relate to dopaminergic innervation. Further studies will be necessary to conclusively evaluate Datl as a candidate gene for $p c d$.

Acknowledgments. We thank the University of Michigan Reproductive Science Center Molecular Biology Core (NIH P30-GD18258) for technical assistance. This work was supported by the National Institutes of Health grant NIH 1R01-HD26490-010A (S.A. Camper) and the intramural program of the NIDA.

\section{References}

Buckwalter, M.S., Katz, R.W., Camper, S.A. (1991). Localization of the panhypopituitary dwarf mutation $(d f)$ on mouse chromosome 11 in an intersubspecific backcross. Genomics 10, 515-526.

Dietrich, W., Katz, H., Lincoln, S.E., Shin, H.-S., Friedman, J., Dracopoli, N., Lander, E.S. (1992). A genetic map of the mouse suitable for typing intraspecific crosses. Genetics 131, 396-423.

Giros, B., Mestikawy, S.E., Godinot, N., Zheng, K., Han, H., Feng, T.Y., Caron, M.C. (1992). Cloning, pharmacological characterization, and chromosome assignment of the human dopamine transporter. Mol. Pharmacol. 42, 383-390.

Justice, M.J., Stephenson, D.A. (1992). Mouse Chromosome 13. Mammalian Genome 3(Suppl.), S195-S205.

Mullen, R.J. (1977). Site of pcd gene action and Purkinje cell mosaicism in a cerebella of chimaeric mice. Nature 270, 245-247.

O'Gorman, S., Sidman, R.L. (1985). Degeneration of thalamic neurons in "purkinje cell degeneration" mutant mice. I. Distribution of neuron loss. J. Comp. Neurol. 234, 277-297.

Pauls, D.L., Leckman, J.F. (1986). The inheritance of Giles del Ia Tourette's syndrome and associated behaviors. N. Engl. J. Med 315, 993-997.

Ritz, M.C., Lamb, R.J., Goldberg, S.R., Kuhar, M.J. (1987). Cocaine receptors on dopamine transporters are related to self-administration of cocaine. Science 237, 1219-1223

Smith, S.S., O'Hara, B.F., Persico, A.M., Gorelick, D.A., Newlin, D.B., Vlahov, D., Solomon, L., Pickens, R., Uhl, G.R. (1992). Genetic vulnerability to drug abuse: the dopamine $\mathrm{D}_{2}$ receptor Taq I BI RFLP appears more frequently in polysubstance abusers. Arch. Gen. Psychiatry $49,723-727$.

Vandenbergh, D.J., Persico, A.M., Hawkins, A.L., Griffin, C.A., Li, X., Jabs, E.W., Uhl, G.R. (1992). Human dopamine transporter gene (DAT1) maps to chromosome 5p15.3 and displays a VNTR. Genomics 14, 1104-1106. 